MAGNANR]

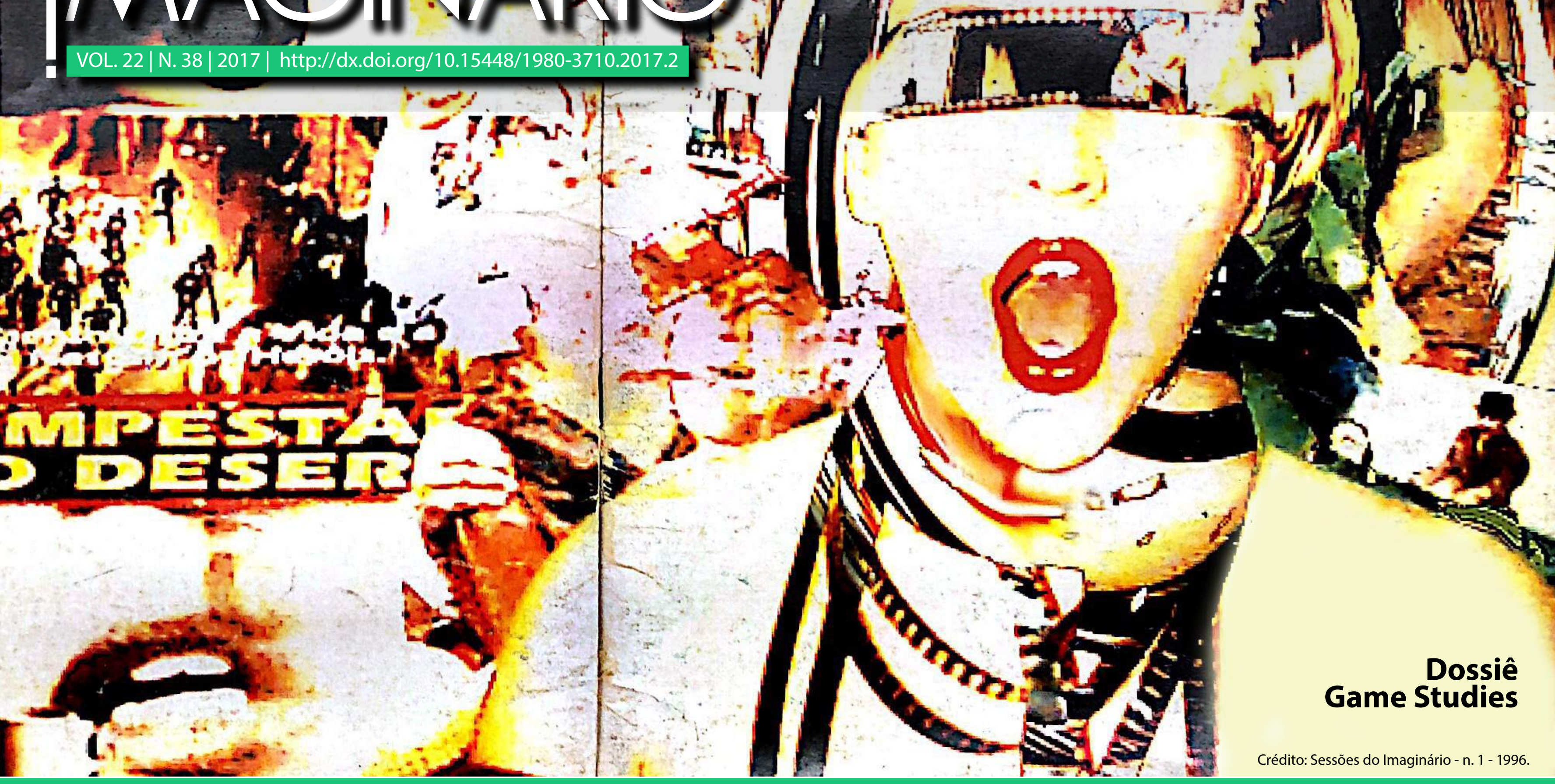

A estética do imaginário no cinema

Demian Garcia e André A. Medeiros P. 81
Materialidades fílmicas, magia e montagem

Ednei de Genaro
Videogames, transgressão e criatividade no Brasil

Emmanoel Ferreira 


\section{A Poética Estética da Memória em Valsa com Bashir}

\author{
Memory's Poetic Aesthetics in \\ Waltz with Bashir
}

\section{Carla Elizabeth Pereira e Lyra' $\square$}

Igor Alexandre Capelatto $\left.{ }^{2}\right]$

\section{Resumo}

Este presente artigo tem como ponto de partida o filme Valsa com Bashir (Vals Im Bashir, 2008) de Ari Folman para uma reflexão sobre a estética do documentário de animação como ferramenta de construção de história, política e memória. De acordo com o release oficial (DVD e Bluray), o diretor Ari Folman (2008), que participou como soldado da segunda guerra do Líbano em 1982, examina suas próprias culpas para abordar os problemas da reconstituição da memória dos episódios dramáticos que culminaram no massacre dos campos de Shabra e Shatila, em que teriam morrido 3.000 refugiados palestinos. Com o fato da imagem fotográfica das câmeras não "darem conta" de representar a memória em si, Folman recorrerá ao desenho, segundo o autor, como estética capaz de acionar memórias que a fotografía não é capaz de alçar.

\section{Palavras-chave}

Documentário; animação; memória; estética.

\section{Abstract}

This article has as its starting point the film Waltz with Bashir (Vals Im Bashir, 2008) by Ari Folman for a reflection on the aesthetics of the animation documentary as a tool for the construction of history, politics and memory. According to the official release (DVD and Bluray), director Ari Folman (2008), who participated as a soldier in the second Lebanon war in 1982, examines his own faults to address the problems of rebuilding the memory of the dramatic episodes that culminated in the massacre of the camps of Shabra and Shatila, in which 3,000 Palestinian refugees were killed. With the fact that the cameras' photographic image does not "account" for representing the memory itself, Folman recreates drawing, according to the author, as an aesthetic capable of triggering memories that photography can't lift.

\section{Keywords}

Documentary; animation; memory; aesthetics. 
Documentário Animado: a estética da subjetividade

[Imaginar é a] singular capacidade de distanciamento do mundo dos objetos e de recuo para a subjetividade própria, [...] capacidade de se tornar sujeito de um mundo objetivo (Flusser, 2008 p. 163).

De acordo com Martins (2006), o documentário animado pode ser definido como um filme de situações e fatos reais registrados em suporte eletrônico utilizados como base para posterior intervenção gráfica da animação, que muitas vezes é computacional. Quase sempre apresenta a "valorização de aspectos subjetivos das situações a partir da representação das personagens e dos cenários" (Martins, 2006). Segundo a autora, esta valorização de aspectos subjetivos determina uma narrativa que concentra em cada elemento de sua estrutura: personagem, ação, ambiente, espaço e tempo, possibilidades de interpretação. Ou seja, busca revelar com o discurso verbal (entrevistas, narração em off) e os recursos gráficos a intensidade do que está sendo relatado, na maioria dos casos, bio-

Figura 1: Frame de Valsa para Bashir. Fonte: Folman (2008).

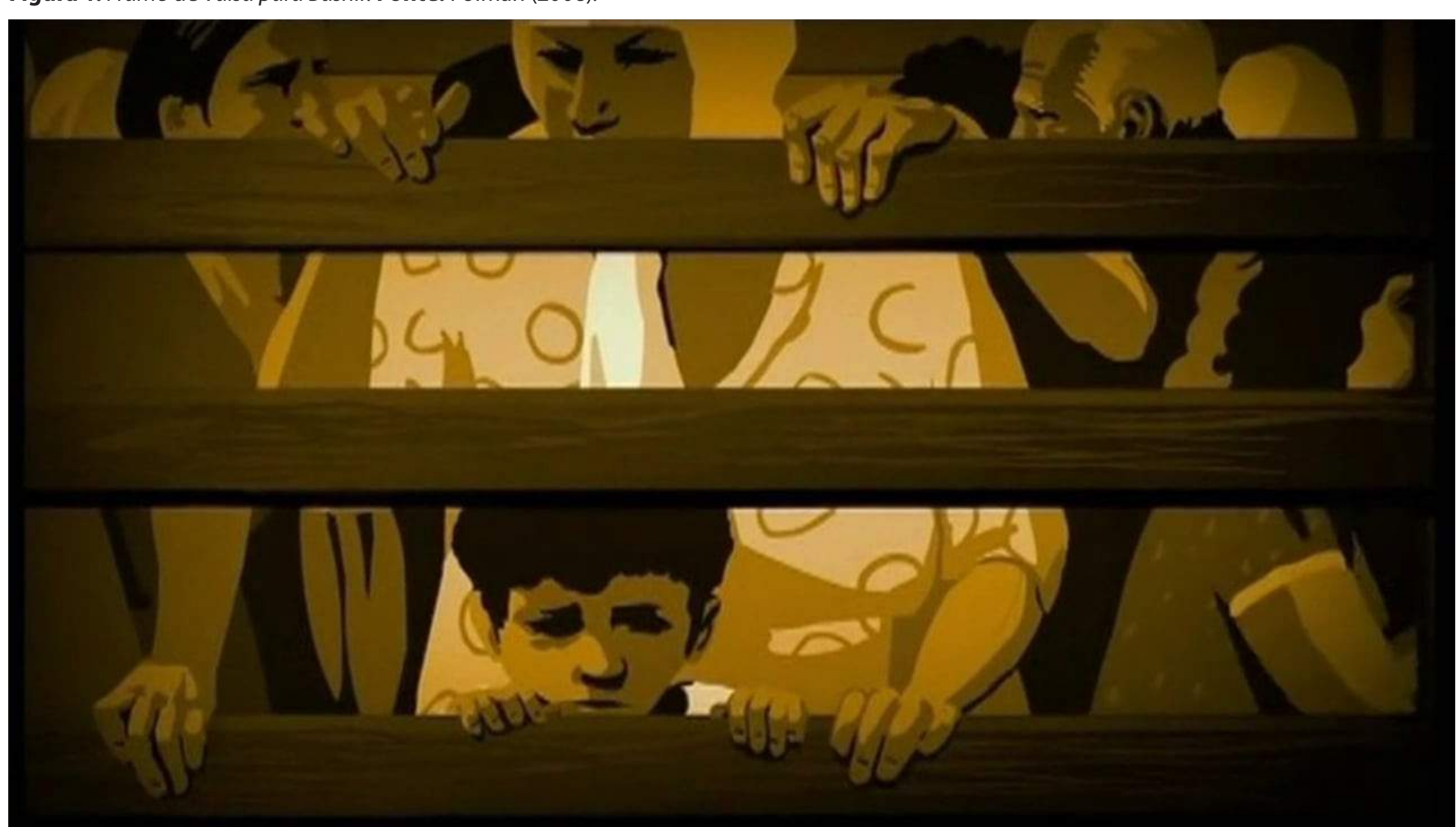

grafias e autobiografias de animadores.

Este é o caso de Valsa com Bashir (Vals Im Bashir, Ari Folman, 2008), que narra as memórias do seu diretor/ autor que explica com suas palavras no making of a dificuldade na definição do "gênero" do seu filme:

\begin{abstract}
Eu penso que fui tolo quando declarei que era um documentário animado cinco anos atrás. Eu acredito que a indústria do cinema é tão limitada e estúpida e não aberta para novas ideias. Quando eu tentei captar recursos eu fui para os fundos de documentário e eles me falaram: "Escute, se é animado não pode ser documentário. Procure os fundos de animação. Eles não podem dar certo juntos". Eu fui para animação e eles me disseram se é um documentário, você deve procurar os fundos de documentário. E eu fiquei parado no meio durante um longo período (Folman, 2008).
\end{abstract}

Por outro lado, seriam "convenções" do documentário: não-direção de atores (depoimento espontâneo), uso de cenários naturais, imagens de arquivo, câmera ao ombro, ausência de roteiro preestabelecido. Estes aspectos utilizam a convenção da linguagem do documentário tradicional. De acordo ainda com Martins (2006), no caso do documentário animado, a entrevista gravada é o roteiro, que define o storyboard e a estrutura da animação que foi a estratégia utilizada pelo diretor. Por sua vez, a preparação - ou "pesquisa e desenvolvimento" - é estabelecida pela definição clara das intenções do documentarista, da abordagem ao tema, da forma como pretende mostrar os locais e as pessoas. Desses elementos, o que mais representa a

162 PORTO ALEGRE | v. 22 | n. 38 | 2017| p. 161-168 Sessões do Imaginário 
dimensão do real do documentário é o depoimento espontâneo em que se baseou o diretor para criar o seu roteiro (ver Figura 1).

Basicamente nós realizamos uma pesquisa e entrevistas e, baseado neste material, eu escrevi um roteiro de noventa páginas que guiou a fala dos entrevistados durante a gravação. Filmamos em estúdio, dramatizamos e imitamos o som em estúdio (Folman, 2008).

A estrutura narrativa implica saber contar uma história, organizar a estrutura dramática em sequências e cenas que se sucedem de modo lógico. Para sustentar a história deve-se ter uma ideia a transmitir. Essa ideia é o que constitui a visão do realizador sobre determinado assunto. Qual seria o fio condutor da narrativa em Valsa com Bashir? São narrados sonhos, pesadelos, recordações e foram entrevistados especialistas no assunto para se entender o funcionamento da memória. O ponto de vista dos soldados e sua relação com a guerra e com a morte - para além dos processos decisórios da história e dos líderes - é o foco da narração até chegar ao local da memória do massacre: Shabra e Satila.

\section{Uma valsa para a libertação da memória}

Sobretudo a lembrança de guerras ou de grandes convulsões internas remete sempre ao presente, deformando e reinterpretando o passado (Pollak, 1989, p. 6).

Priscila Arantes cita Hebert Marcuse ao destacar o poder liberador da arte, que operaria como parte do poder liberador do negativo e ajudaria a "libertar o inconsciente e o consciente mutilados que solidificam o establishment repressivo" (Arantes, 2005, p. 175). Neste contexto, o filme seria também um processo de cura. No caso de Valsa com Bashir, o autor faz referência ao fenômeno do stress pós-traumático - ligação entre os sonhos, realidade e memória - através da entrevista com a Dra. Zahava Solomon, uma psicóloga e pesquisadora israelense no campo do trauma psicológico. Controvérsias da memória ou da história? É através da investigação do seu passado que o autor nos conduz a uma reflexão sobre estes acontecimentos da guerra. Ari Folman desenvolve a sua narrativa quando procura os seus amigos para reconstruir a sua memória individual.
De acordo com a imprensa, embora o massacre, tecnicamente, tenha sido atribuído a falangistas cristãos e libaneses, havia tropas israelenses ocupando aquele país - e sua responsabilidade ou omissão no caso continuam a ser objeto de controvérsia (ver Figura 2).

Em uma reflexão (making of no DVD), Ari Folman discursa sobre o processo da memória indagando sobre ser a memória fruto de uma construção inventada4 ou sendo parte de uma história "real":

Este sonho tem que estar vindo de algum lugar [...] Descobrir coisas sobre mim que eu não sei. É possível eu não conseguir me lembrar de um evento tão dramático? [...] A minha visão do massacre é

163 PORTO ALEGRE | v. 22 | n. 38 | 2017| p. 161-168 Sessões do Imaginário

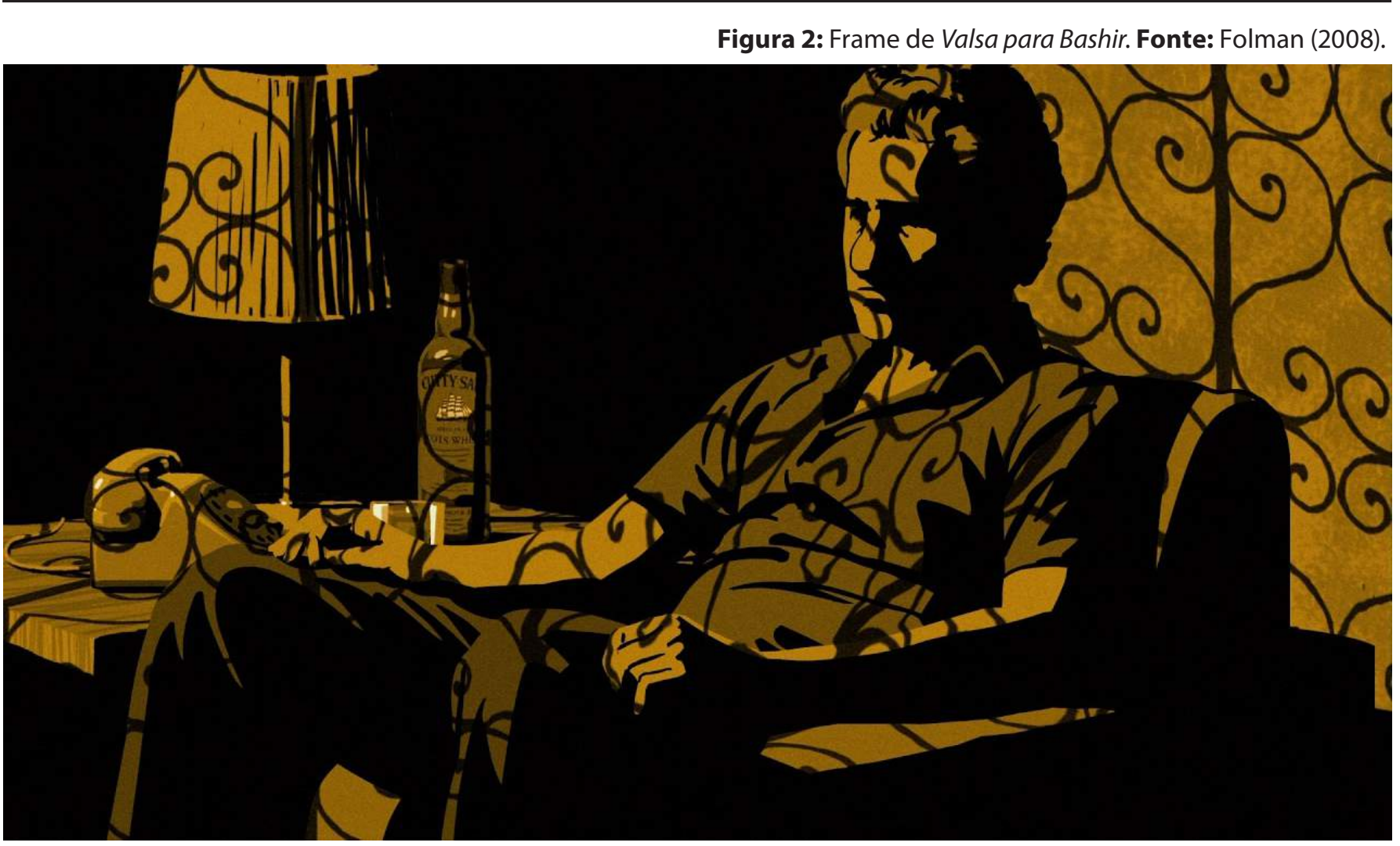


uma coisa inventada? [...] A minha memória está voltando. Eu estou quase me lembrando de tudo (Folman, 2008).

De acordo com Araújo e Santos (2005), a memória opera a partir de um processo seletivo e pode se tornar uma arma política para as vítimas de guerras e genocídios em que o esquecimento estabeleceu sua hegemonia. Nossas memórias, mesmo que "pessoais e intransferíveis", necessitam ser compartilhadas com os nossos pares na sociedade com os quais nos identificamos. Trata-se de uma construção coletiva, um arquivo comum que consultamos conforme vamos vivendo. Não existe memória sem emoção, sendo que esta mo- dula a forma como os dados são guardados. A arte e a estética estimulam as nossas memórias sensorial, de reconhecimento e de conhecimento dos territórios e da história (ver figura 3).

Anamnese de Folman: analogias entre
Memória Individual e Memória Coletiva

Este é com certeza um processo de cura (Folman 2008).

A estética de Valsa com Bashir traz poéticas narrativas que muito remetem a linguagem das comic books europeias (ou as chamadas comic books alternativas

Figura 3: Frame de Valsa para Bashir. Fonte: Folman (2008).

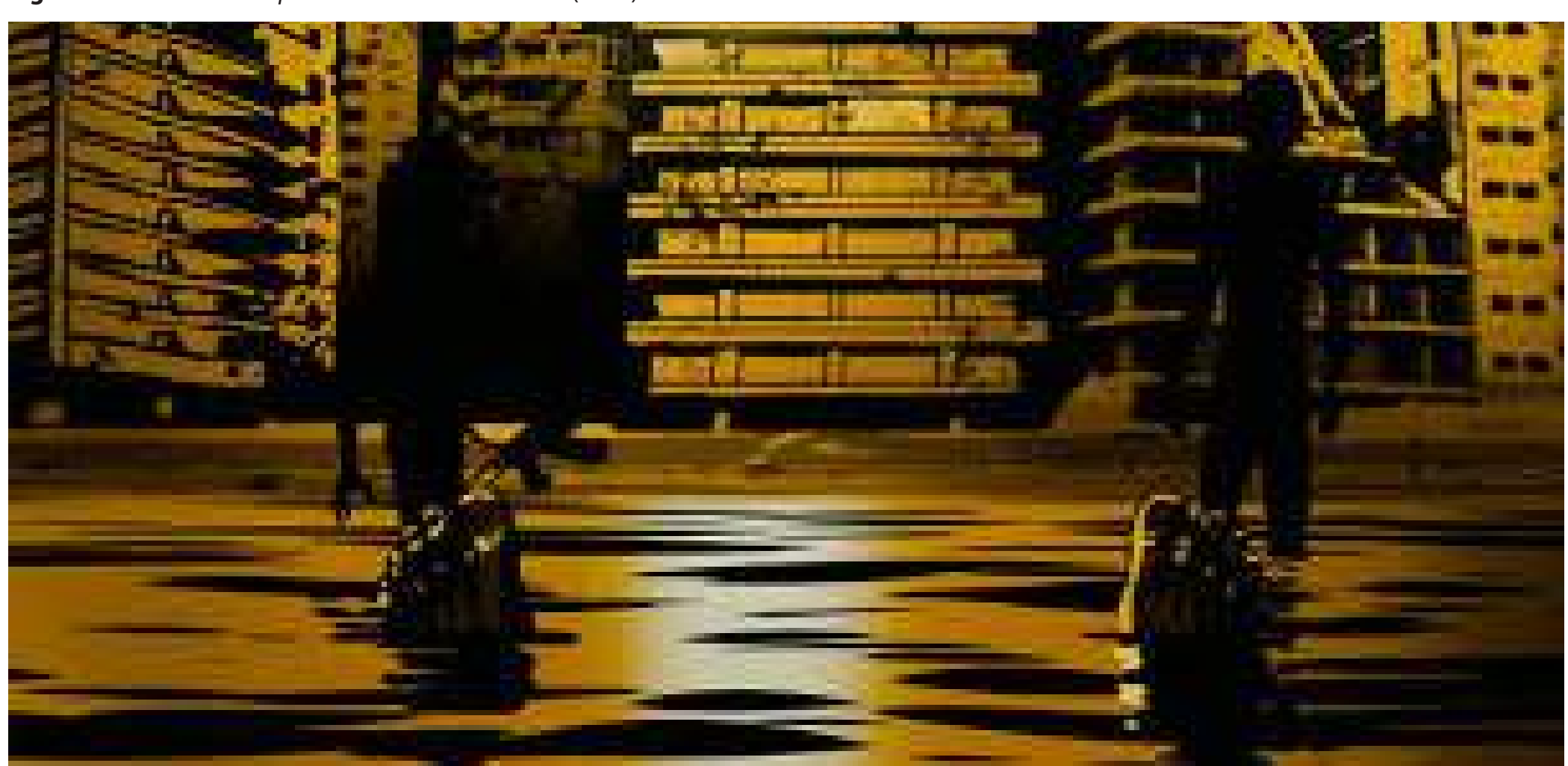

norte-americanas). Ari Folman tem uma formação tanto jornalística quanto audiovisual, mas em sua constituição como comunicador obteve muita referência de histórias em quadrinhos (inspirado por Will Eisner, Folman tem entre outras referências nos quadrinhos de Joe Sacco, Daniel Clowes e Joe Kubert). Sua criação em Valsa com Bashir logo saiu das telas animadas para as páginas impressas, trabalho que contou com a maestria de David Polonsky, artista gráfico que ilustra filme e quadrinhos. Polonsky intervém com a proposta de que a arte do desenho (e da pintura) comunica por meio de imagens que a fotografia não é capaz de alcançar (IMDB, 2008). Segundo Flusser (2008), a imagem da fotografia (still ou em movimento) é a imagem técnica, no sentido de produzida por um aparelho, enquanto a imagem da memória é uma imagem poética, criada pela memória e, portanto, influenciada por formas, gestos, estéticas (re)criadas pela mente humana de maneira que a imagem fotográfica nunca será suficiente para representar a imagem da mente. Talvez, por isso, o desenho se aproxima melhor.

Folman, enquanto pesquisador, recria essa poética dos quadrinhos, tanto na sua versão impressa quanto anteriormente na sua narrativa animada, na qual encontramos essa maestria da composição de quadros que convergem instantes distintos em subjetivos "planos sequências". A ideia do desenho substituindo a imagem fotográfica é a ideia de representar aquilo que a realidade não representa e criar um outro conceito de realidade. Folman e Polonsky nos fazem crer na imagem do desenho muito mais do que na imagem da fotografia, por um processo de representação autoral. Enquanto a fotografia (ainda que tenha um olhar de um autor-fotógrafo-artista) representa o real "tátil",

164 PORTO ALEGRE | v. 22 | n. 38 | 2017 | p. 161-168 Sessões do Imaginário 
o desenho-pintura-gravura representa o "real subjetivo", ou seja, "a realidade que representa a realidade do próprio autor da imagem" (ver Figura 4).

Os quadrinhos possuem essa magia e a animação tem essa poesia: representam não somente o objeto em questão (ser humano e ambiente), mas também uma estética visual (a forma, pressão, volume do traço, as cores e a maneira como texturas, ritmo da movimentação são dispostas tecnicamente). Esta, por sua vez, se torna parte da linguagem, atingindo, segundo Polonsky (IMDB, 2008) possibilidades que a imagem "real" jamais alcança. É como colocar a memória e a emoção em traços (assinatura do artista) que a realidade fotográfica não consegue atingir. Para Flusser (2002, p. 13-14), as imagens técnicas representam janelas e não imagens em si.
A fotografia pode ser utilizada, nesse caso [dos quadrinhos, e por conseguinte, das animações] apenas como uma referência visual primeira do detalhe, para que possa, posteriormente, construir os detalhes de sua imagem através do desenho. Essa é a metodologia de Joe Sacco. Os quadrinhos passam a ser, segundo ele, em função da possibilidade de construção do detalhe, um poderoso meio jornalístico de retratar a realidade. Antes que eu chegasse lá, li numa matéria jornalística algo sobre Gorazde que [sic] chamou minha atenção, mas não conseguia imaginar a cidade na minha cabeça. Eu não sabia se era um vilarejo ou outro tipo de lugar. Quando cheguei lá, vi que era uma cidade de prédios muito altos e complexos de apartamentos. Histórias em quadrinhos podem ser uma grande fonte de informação visual, o que acredito fazer

Figura 4: Trecho da versão em quadrinhos de Valsa para Bashir. Fonte: Folman; Polonsky (2008, p. 73).

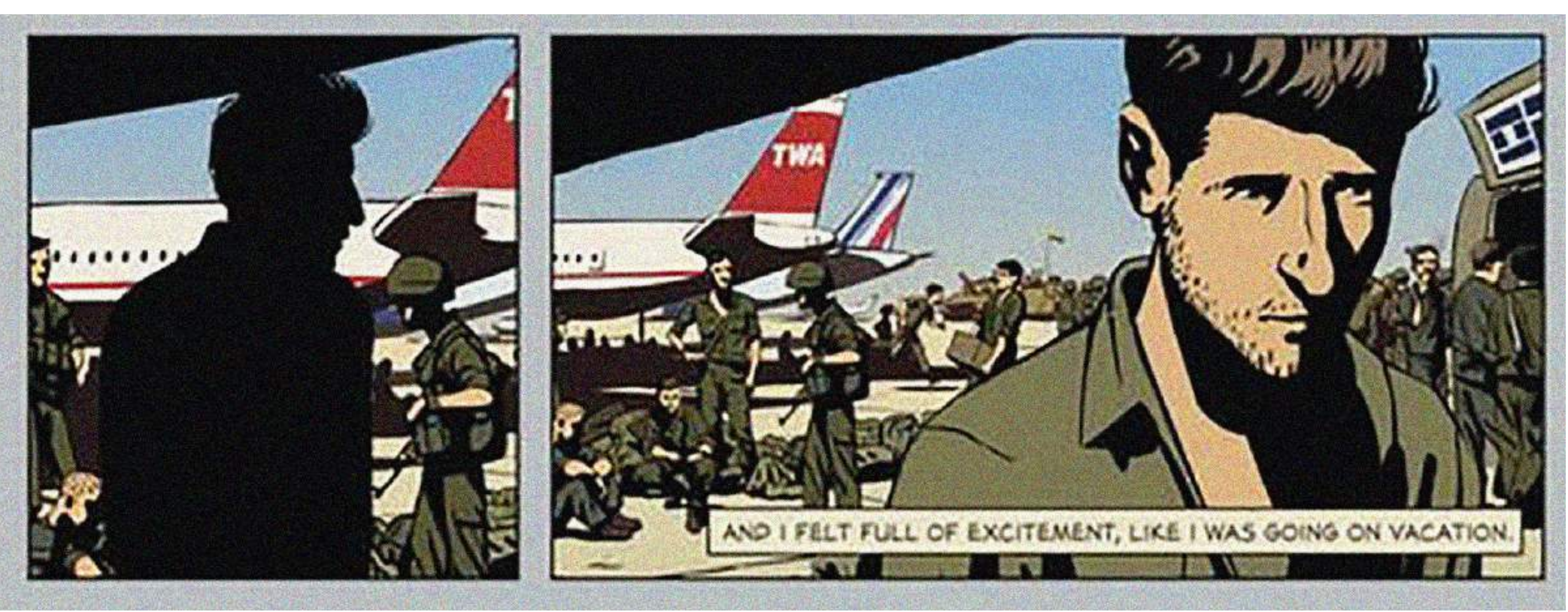

com que um lugar como Gorazde se torne "real" aos olhos do leitor. E não somente o lugar, mas as pessoas, porque no detalhes [sic] no fundo da imagem pode-se ver o que eles vestiam, como eles cortavam a lenha, a extensão dos danos aos seus lares, etc. Histórias em quadrinhos são um meio jornalístico muito atraente. Elas permitem que um senso de tempo e espaço penetre nas imagens repetidas (Muanis, 2006, p. 8).

Através das imagens técnicas vemos um simulacro da realidade, mas não o que essa realidade representa de fato (ou o que Flusser chama de "verdadeira realidade", a ficção pessoal de cada indivíduo): "o caráter aparentemente não-simbólico, objetivo, das imagens técnicas faz com que seu observador as olhe como se fossem janelas, e não imagens" (Flusser, 2002, p. 13-14); ou seja, como signos concretos, e portanto não representativos e abstratos.

Representação é a tradução mental de uma realidade exterior percebida e liga-se ao processo de abstração. O imaginário faz parte de um campo de representação e, como expressão do pensamento, se manifesta por imagens e discursos que pretendem dar uma definição da realidade (Le Goff apud Makowiechy, 2003, p. 4).

Talvez por conta do imaginário se manifestar por imagens, que a animação e os quadrinhos tanto tenham atraído Folman - através da poética-estética do desenho na animação ou nos quadrinhos, vemos a re-

165 PORTO ALEGRE | v. 22 | n. 38 | 2017| p. 161-168 Sessões do Imaginário 
alidade de Folman, vemos através de sua mente (e dos demais entrevistados), a sua memória e não uma realidade "crua" e "genérica". Com a animação (e com os quadrinhos), Folman (e Polonsky) auferem, conforme coloca Martins (2006), a valorização de aspectos subjetivos.

\section{Recuperação da memória: a realidade para além das controvérsias}

Que os sonhos se realizem e os pesadelos passem (trecho da música cantada pelos soldados israelenses no filme Valsa com Bashir, 2008).

O trauma é um dos conceitos-chave da Psicanálise e o trabalho psicanalítico existe em função do traba-
Iho de recomposição do evento traumático. O que é o evento trauma? O trauma é justamente uma ferida na memória. O trauma, para Freud (apud Fulgencio, 2004), é caracterizado pela incapacidade de recepção de um evento transbordante - ou seja, assim como no caso do sublime: trata-se, aqui também, da incapacidade de recepção de um evento que vai além dos ,'limites" da nossa percepção e torna-se, para nós, algo sem-forma. Essa vivência leva posteriormente à compulsão a repetição da cena traumática. $O$ trauma, explica Freud, advém de uma quebra do Reizschutz (pára-excitação), provocada por um susto (schrek) que não foi amparado pela nossa Angstbereitschaft (estado de prevenção à angústia).

A trajetória de "cura" e recuperação da memória do autor é simbolizada através da realidade das cenas reais

Figura 5: Frame de Valsa para Bashir. Fonte: Folman (2008).

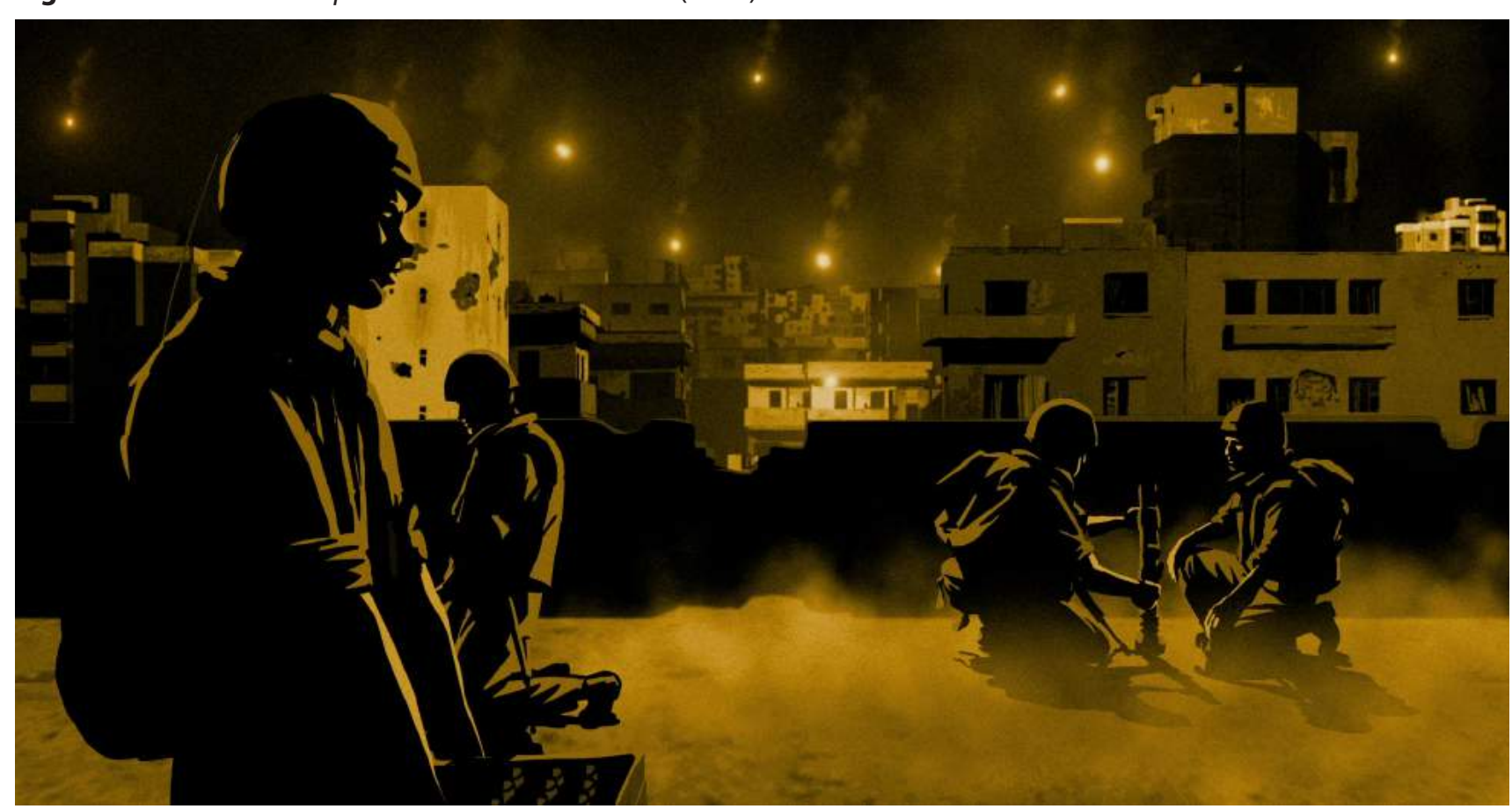

do massacre de Sabra e Shatila, onde as mulheres retornam ao acampamento e avistam o quadro de mortes de crianças e outros civis palestinos e muslims libaneses, entre 16 e 18 de setembro de 1982, pelo partido Kataeb e milícias do grupo das forças cristãs, depois do assassinato do líder falangista e presidente eleito Bachir Gemayel. Foram cerca de 800 pessoas de acordo com fontes internacionais, e até 3.500 de acordo com fontes Palestinas. Israel seria diretamente responsável pelo evento e Ariel Sharon teria responsabilidade pessoal pelo massacre por ter permitido a entrada dos Falangistas nos campos e fornecido armas e equipamentos para os Falangistas, assim como o transporte destes para os campos.

\section{Reminiscências de uma valsa com} Bashir

A memória é seletiva. Nem tudo fica gravado. Nem tudo fica registrado (Pollak, 1992, p. 204).

Qual o significado de uma animação na recuperação da memória? Que aspectos de transmutação da realidade carrega esta técnica que a diferencia de outros gêneros? Em Valsa com Bashir, concluímos que a animação é redentora; toda a combinação de movimentos, câmera e, principalmente da trilha sonora, ajudam a compor esta intenção do autor. Uma voz monológica que trilha um roteiro baseado em depoimentos reais de amigos - um diálogo necessário para a recuperação da consciência (ver Figura 5).

O processo criativo de Ari Folman complexifica a tarefa de produção documental na medida em que reencena os diálogos para a animação. Depuração de vozes, técnicas e exploração dos limites da ficção e não

166 PORTO ALEGRE | v. 22 | n. 38 | 2017 | p. 161-168 Sessões do Imaginário 
ficção, o que se adequa sempre muito bem quando o objeto é a guerra e sua realidade. Como coloca Nichols (2005), todo filme é uma forma de discurso que fabrica seus próprios efeitos, impressões e pontos de vista. A animação abre espaço para o espectador, pois amplia as dimensões da realidade/ficção/sonho. Temos a sensação - assim como muitos soldados no Líbano - de estar vendo uma realidade em outra dimensão. $O$ choque vem com as imagens reais/imagens de arquivo para, então, finalmente sentirmos todo o trauma dos soldados e a intenção e motivação de Ari Folman para realização do seu filme.

\section{Referências}

ARANTES, Priscila. Arte e Mídia: Perspectivas da estética digital. São Paulo: SENAC, 2005.

ARAÚJO, M. SANTOS, M. Arte e Mídia: Perspectivas da estética digital. São Paulo: SENAC, 2005.

FLUSSER, Villém. Filosofia da caixa preta. Rio de Janeiro: Relume Dumará, 2002.

O universo das imagens técnicas: elogio da superficialidade. São Paulo: Annablume, 2008.

FOLMAN, A; POLONSKY, D. Waltz with Bashir. Israel: Sony Pictures Classics, 2008.

FULGENCIO, Leopoldo. A noção de trauma em Freud e Winnicott. Natureza humana, v. 6, n. 2, 2004. p. 255270.
IMDB. Valsa com Bashir (2008). Disponível em: <http:// www.imdb.com/title/tt1185616/>.Acessoem:23set.2017.

MARTINS, Í. O documentário animado "Ryan" e o psicorrealismo. Trabalho apresentado ao GT5 - Tecnologias e Estéticas da Comunicação. 10. Congresso de Estudantes de Pós-Graduação em Comunicação do Rio de Janeiro, 2006

MAKOWIECHY, S. Representação: a palavra, a ideia, a coisa. Cadernos de Pesquisa Interdisciplinar em Ciências Humanas, v. 4, n. 57, 2003. p. 2-25.

NICHOLS, B. Introdução ao Documentário. Campinas: Papirus, 2005.

MUANIS, Felipe. Imagem, cinema e quadrinhos: linguagens e discursos de cotidiano. Caligrama. São Paulo, v. 2, n. 1, 2006

ORIGEM DA PALAVRA. Disponível em: <http://origemdapalavra.com.br>. Acesso em: 3 out. 2017.

POLLAK, M. Memória, Esquecimento e Silêncio. In: Estudos Históricos, Rio de Janeiro, v. 2, n. 3, 1989, p. 3 - 15. Memória e identidade social. In: Estudos Históricos, Rio de Janeiro, v. 5, n. 10, 1992, p. 200-212.

SCHMIDT, Maria Luisa Sandoval; MAHFOUD, Miguel. Halbwachs: memória coletiva e experiência. Psicologia USP, v. 4, n. 1-2, 1993, p. 285-298.

\section{Referências audiovisuais}

FOLMAN, Ari. NAHLIELI, Yael. Valsa com Bashir. [Vídeo]. Produção de Yael Nahlieli. Direção de Ari Folman. Israel, França, Alemanha, Estados Unidos, Austrália, Suíça, Finlândia, Bélgica, Austrália: Bridgit Folman Film Gang, Les Films d'Ici, Razor Film Produktion GmbH. 2008, 90 min. color. son.

\section{Notas}

1 Doutora em Memória Social pela Universidade Federal do Estado do Rio de Janeiro (2016). Mestre em Ciência Política pela Universidade Federal de Pernambuco (1998). (Universidade Federal do Estado do Rio de Janeiro - Av. Pasteur, 458. Urca. CEP: 22290-240. Rio de Janeiro/RJ).Email: clyra2@gmail.com.

2 Doutor em Multimeios pela Universidade Estadual de Campinas (2018). Mestre em Multimeios pela Universidade Estadual de Campinas (2011). Professor de Cinema nos cursos de graduação e pós-graduação (professor convidado) e Extensão na Universidade Estadual de Campinas (Programa de Pós-Graduação em Multimeios - UNICAMP - Rua Elis Regina, 50. Cidade Universitária „Zeferino Vaz“. Barão Geraldo. CEP: 13083-854. Campinas/SP). E-mail: capuccinoprod@gmail.com.

3 Valsa com Bashir narra O lugar da memória-a Segunda Guerra do Líbano: A Guerra do Líbano teve quatro etapas principais: 1) de 1975 a 1977 com enfrentamentos e massacres entre as comunidades religiosas; 2) uma intervenção síria por petição do Parlamento Libanês entre 1977 e 1982 caracterizada por uma intervenção israelense no sul do país mediante a Operação Litani 
e; 3) uma outra etapa de 1982 a 1984 com a invasão de Israel e a tomada de Beirute. Na década de oitenta, a maior parte de Beirute foi deixada em ruínas como resultado do massacre de Karantina realizado por milícias cristãs libanesas em 1976, dos bombardeios do exército sírio aos bairros cristãos em 1978 e 1981. A quarta etapa, por fim, seria a da invasão israelense que expulsou a Organização pela Libertação da Palestina (OLP) do território libanês em 1982 ocorrendo em seguida o período de intervenção das Nações Unidas entre 1984 e 1990. As milícias cristãs em geral eram grupos de tendência política de direita. Todas as principais milícias cristãs eram dominadas pelos maronitas enquanto que outras seitas cristãs desempenhavam um papel secundário. A mais poderosa destas milícias foi a Kataeb ou Partido das Falanges Libanesas, um partido de direita política do Líbano fundado em 1936 por Pierre Gemayel cujo filho Bashir Gemayel constituiu uma organização paramilitar com outras pequenas milícias cristãs que foi chamada de Forças Libanesas. Em 1982, Israel invadiu o Líbano e forçou a retirada da OLP e das organizações armadas palestinas. Bashir Gemayel foi eleito como presidente com apoio de lsrael, entretanto é assassinado antes de tomar posse juntamente com outros 40 falangistas por um agente de inteligência da Síria. No dia 15 de setembro de 1982, Israel ocupou Beirute. Enquanto isto Israel cercou o campo de refugiados palestinos e deixou as Forças Libanesas, braço armado das Falanges e lideradas por Elie Hobeika, entrarem nos campamentos Sabra e Chatila de refugiados palestinos nas noites de 16 a 17 de setembro, assassinando milhares de refugiados e civis desarmados.
4 "Memória Iventada". Em Valsa com Bashir, a memória com a qual deparamos é a memória histórica, memória que constitui no encaixe de peças de um quebracabeças, que é a biografia de uma pessoa, um grupo, uma sociedade, uma nação, da natureza. Segundo Schmidt e Mahfoud (1993), a memória histórica oferece uma construção inventada do passado. "Inventar"- do Latim inventio, "achado, descoberta", de invenire, "descobrir, achar", formado por in, "em", mais venire, "vir". Com o sentido atual, de "coisa feita previamente nãoexistente", é do século XVI (Origem da Palavra, 2017). 